\title{
Compounding in Tai Ahom: A Descriptive Study
}

\author{
Dipima Buragohain \\ Centre for International Languages, Universiti Malaysia Perlis \\ Tel: 60-111-518-9560Ｅ-mail: dipima@unimap.edu.my
}

Received: September 9, 2019 Accepted: October 16, 2019 Published: October 18, 2019

doi:10.5296/elr.v5i2.15564

URL: https://doi.org/10.5296/elr.v5i2.15564

\begin{abstract}
Compounding is a frequent phenomenon in Tai-Kadai languages when it comes to word formation processes. Numerous individual as well as comparative researches conducted on various languages of the Tai-Kadai group provide evident testimonials to the prolific use and functionality of compounding in terms of its varied syntactic, semantic, and anthropological attributes. Tai Ahom - a Southwestern language from the Tai-Kadai group, spoken in ancient Assam, India and now extinct - demonstrates a similar phenomenon. The current study looks into the aspect of compounding in Tai Ahom highlighting its types and structures while adopting a descriptive approach of analyzing the field data. Findings report that Tai Ahom demonstrates semantic and syntactic compounds along with gender marking while using reduplication as one of its most common word formation processes.
\end{abstract}

Keywords: Tai Ahom language, Tai-Kadai languages, Compounding, Assamese language, Dead language

\section{Introduction}

Compounding is a frequent phenomenon of word formation processes in Tai-Kadai languages in terms of its varied syntactic, semantic, and anthropological attributes. Tai Ahom - a Southwestern language from the Tai-Kadai group - demonstrates a similar phenomenon. Known to be an old language from the group and once spoken by the Ahom community in Assam, India, Tai Ahom is now extinct. Although there are over 8 million Assamese people belonging to the Ahom community, the language is no longer spoken by them as the latter switched to Assamese - the dominant language of the region from the Indo-Aryan language family. However, with limited linguistic knowledge, Tai Ahom is still used by a handful of people of the priestly classes of the community, the semi-speakers (Buragohain, 2018), in religious ceremonies.

The study of Tai Ahom is relevant for its historical significance for the fact that the historical records of the 600 year-old Ahom Dynasty are preserved in Ahom script available in a variety of manuscripts and anthologies, which are the most authentic sources of the Ahom Dynasty 
(Buragohain, 2013). The manuscripts are also relevant resources to understand and analyze the structure of the dead language.

In the context of the basic structure of the language, Tai Ahom is monosyllabic and isolating in nature, and every word retains its individual form. This prominently makes word formation a very significant and common aspect of the language. The most important and frequent feature of word formation processes in Tai Ahom is compounding. The current study aims to investigate and describe the aspects of compounding in Tai Ahom. It discusses the varied types and structures of compounding and other word formation processes in Tai Ahom.

\section{The Tai Ahom Language}

Tai Ahom is an extinct language now. But it was actively used during the reign of the Ahom Dynasty (1228AD-1826AD) in the Brahmaputra Valley. Tai Ahom is no longer spoken by the people of the Ahom community. The community has over 8 million people of Ahom descent but only a few hundreds of them are 'speakers' or rather 'semi-speakers' (since they use it in limited contexts with limited linguistic knowledge) belonging to the priestly classes. They have limited linguistic knowledge of it and do not use the language in their daily life. Its only use can be observed in religious functions and rituals celebrated by the Ahom community (Phukan, 1966; Barua \& Phukan, 1991; Gohain, 1997; SIL International, 2002). The Ahom priestly community is usually dispersed across the Upper Assam area including Sivasagar, Golaghat, Dhemaji, Jorhat, Dibrugarh, and Lakhimpur.

\section{Research Design}

The current study adopts a descriptive approach to investigate and analyze the varied types and structures of compounding in Tai Ahom. The discussion also entails compounding and word formation processes in other Tai-Kadai languages - Bouyei of the Northern Tai group and Thai of the Southwestern Tai group. The linguistic data for the current paper has been collected from the Ahom community - who are the semi-speakers (Buragohain, 2018) - in the Sivasagar district, more particularly from the villages of Patsaku, Bokotha, and Ramugaon. Phonetic transcription with IPA symbols (approved by SIL) is used for describing the words and structures. This is also in line with the field linguistic approach of data collection as discussed in Abbi (2001).

\section{Terms and Concepts}

This study entails a descriptive research on the aspects of compounding in Tai Ahom while highlighting the compound types frequently found in the language. Some of the terms and concepts of compounding used in this study are briefly discussed below.

Free morpheme: These morphemes have their own independent meaning which can be attributed partially or completely to form the meaning of the new compound.

Bound morpheme: These morphemes do not have any independent meaning and can be added to free morphemes to form the meaning of the new compound. These are "grammatically assimilated learned compounds" (Fasold, 1968, p. 195).

Semantic compounds: Compound constructions in Tai-Kadai languages based on their semantic properties can be categorized as: Endocentric, Exocentric, and Copulative. Endocentric compounds are those compounds where one morpheme functions as the head and the other modifies it (e.g., boathouse, blackboard, etc.). In case of exocentric compounds, 


\section{Macrothink}

none of its morphemes acts as a head (e.g., white-collar, skinhead, etc.). Copulative compounds are compounds where both morphemes weigh equally as heads (e.g., sleepwalk, bittersweet, etc.).

Syntactic compounds: Compound constructions in Tai-Kadai languages based on their syntactic properties can be categorized as: Noun-Noun, Noun-Verb, Noun-Adjective, Verb-Verb, and so on. Various compound constructions of Tai-Kadai languages are briefly discussed in the next section.

\section{Compounding in Tai-Kadai Languages}

Compounding is a process of word formation that creates compound lexemes by juxtaposing free morphemes (Arcodia et al., 2010). These morphemes have their own independent meaning which can be attributed partially or completely to form the meaning of the new compound. A common phenomenon noticed across Tai-Kadai languages is that these are usually monosyllabic tonal languages with many of them being typically of the isolating nature. Compounding thus becomes significant in the word formation processes in these languages when "compounding of several types is active and common" (Diller et al., 2008).

\subsection{Bound Morphemes}

In terms of monosyllabicity, Tai-Kadai languages uniformly display compounding of free morphemes. However, bound morphemes are also an interesting phenomenon contributing productively to word formation processes. Bouyei - a language spoken by the Bouyei ethnic group in Southern China and a classified member of the Northern Tai group of Tai-Kadai languages - uses bound morphemes for word formation (Boonsawasd, 2012). /tuy / - usually referring to 'mutual' - is a bound morpheme added as a prefix to the root words to form new compounds. For instance (Boonsawasd, 2012, p. 49),

1. /tun-t6ai/

mutual-love

'to love each other'

2. /tuү-puy /

mutual-meet

'to meet together'

Similarly, /lay / - usually referring to 'next' - is a bound morpheme added as a suffix to the root words to form new compounds. For instance (Boonsawasd, 2012, p. 51),

3. /pi-lay /

year-next

'next year'

4. /xat-lay /

morning-next

'next morning'

\subsection{Semantic Compounds}

In case of semantic compounds, Tai-Kadai languages show endocentric, exocentric, and copulative compound constructions. Such compound constructions can consist of a head 


\section{Macrothink}

morpheme and a constituent part, or two semantic heads, or even two non-heads. For example, in Bouyei (Boonsawasd, 2012, pp. 51-54),

5. /xap-fai/

box-tree

'coffin'

6. /me-va:i/

mother-buffalo

'cow'

7. /h`oykhrua/

room+kitchen

'kitchen'

8. /phîchai /

older sibling+human male

'elder brother'

9. /khanchat/

CL (for long-handled objects) + fan

'large fan'

10. /pèt-kài /

duck-chicken

'barnyard fowl'

11. /phǔa-mia /

husband-wife

'married couple'

Endocentric compounds sometimes contain only the meaning of the head while delexicalizing the other morpheme. For instance, in Tai Ahom,

\subsection{Delexicalized}

12. /khron-lin /

goods-monkey

'goods and belongings'

Reverse process can also be seen in the form of lexicalization in Tai Ahom where an empty morpheme can be compounded with a free morpheme. For example,

\subsection{Lexicalized}

13. /phrat-to /

(?)-boundary

'to extend the boundary'

Exocentric compounds with no constituent morphemes as head are common in Thai too - a prominent member of the Southwestern Tai languages. For example (Fasold, 1968), 


\section{Macrothink}

14. /banna-rák/

writings-to protect

'librarian'

\subsection{Syntactic Compounds}

In terms of syntactic compounds, noun-noun compounds are a common phenomenon in Tai-Kadai languages. Noun compounds are common in Bouyei (Boonsawasd, 2012). For instance,

15. /zi-na /

farmland-paddy field

'field'

16. /tay-yon /

light-daytime

'sun'

Fasold (1968) discusses and analyzes Thai compounds at a larger length, particularly the abundant use of compound nouns which are usually derived from sentences with relative clauses. For example,

\section{7. /kradan-dam /}

board-black

'blackboard'

This is possibly derived from the following construction:

18. /kradan-thi-dam /

board-REL-black

'board which is black'

19. /khǒn-k’e? /

hair-lamb

'lamb's wool'

This is possibly derived from the following construction:

20. /khǒn-thi-k'c?-mi /

hair-REL-lamb-have

'the hair which a lamb has'

In other words, Thai shows minimal distinction between the formative structure of noun (relative) phrases and noun compounds. More specifically, noun-noun compounds in Thai are of the possessive type, as shown in the examples above. Thai noun compound types are structured as follows:

Noun + Verb

Noun + Verb with object

Noun + Noun (head and attribute)

Noun + Noun (coordinate compound) 


\section{Macrothink}

Noun-verb compounds are the most frequent compound types in Thai (Fasold, 1968). These compounds usually include adjectival or non-adjectival (where the verb is intransitive) verbs. For example,

21. /nák-khian /

expert-to write

'writer'

22. /can-bin /

plate-to fly

'flying saucer'

23. /nám-h`om/

water-to be fragrant

'perfume'

5.6 Other Compounds

More examples of other compound constructions in Tai-Kadai languages are provided below.

Verb-Verb

\section{Bouyei}

24. /nen-zan /

to look-to see

'to look'

\section{Tai Ahom}

25. /khen-bai/

to save-to put

'to help'

\section{Verb-Noun}

\section{Bouyei}

26. /6a:u-za:n/

to begin-house

'to get married'

27. /nи-сш /

to stuck-air

'to breathe in'

28. /6иау-сш /

to release-air

'to breathe out'

\section{Tai Ahom}

29. /kap-to /

to join-boundary

'to join something broken' 


\section{Macrothink}

\subsection{Compounding in Tai Ahom}

While discussing the various word formation processes in Tai languages, Grierson (1903) points out the typical presence of compounding in Siamese-Chinese languages. Compounds are widely used in the Tai Ahom language as well. Due to the monosyllabic nature as well as phonemic tonal presence in the language, compounds play a very significant role in the word formation process of Tai Ahom, and are extensively used in historical documents, inscriptions, copperplates, and chronicles during the Tai Ahom rulers of Assam.

Compounds in Tai Ahom demonstrate both semantic and syntactic formation. Sometimes, compounds are formed by using the words of identical meaning. For instance, the two words /di / and /yam / convey, among all other connotations, a common meaning 'good' and the compound /di-yam / is formed by combining these two words which is employed to mean 'good' and nothing else. Another example is the explanation of the word 'rule'. There is no single Tai Ahom word for expressing the verb 'to rule'. This verb may be expressed with the

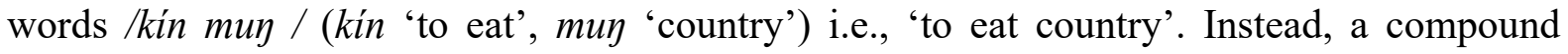

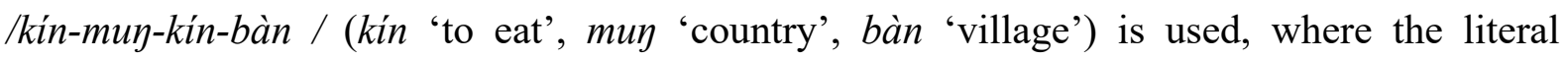
meaning is 'to eat country and village'. Similarly, the compound /ray-kan-ploy-kan / (ray 'to consult', kan 'mutual', ploy 'to decide', i.e., 'mutual decision after consultation') is more relevant in terms of meaning than the compound / $\mathrm{rar}-\mathrm{kan} /$; the compound /phai-muy-phai-bàn / (phai 'to roam', muy 'country', bàn 'village', i.e., 'to roam the country') is more relevant in terms of stylistics than the compounds /phai-muy / or /phai-muy-bàn /.

At a lexical level, Tai Ahom compounds are usually formed by juxtaposing two or more words, ranging up to a combination of six or even more words. For example,

\section{a) Two-word compounds:}

30. /pi-nэy/

elder brother-younger brother

'siblings'

31. /nay-cao /

sister-young girl

'young girl'

32. /luk-lan /

son-grandson

'descendants'

33. /muy-bàn /

country-village

'the whole kingdom'

\section{b) Three-word compounds:}

34. /tay-bàn-muy /

all-village-country

'in the whole country' 


\section{Macrothink}

35. /khup-ma-poi /

kneel-come-prostrate

'to come and prostrate in the Tai way'

36. /hit-mun-khen /

do-rejoice-night

'marry making at night'

c) Four-word compounds:

37. /mau-ru-mau-sey /

priest-knowledge-priest-sacred

'chief priest'

38. /hit-khru-hit-biy /

do-canal-do-rampart

'to build fortress'

39. /tay-pi-tay-noy /

all-elder-all-younger brother

'all the brothers'

d) Five-word compounds:

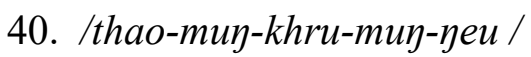

old-country-officer-country-elder person

'elder persons of the country'

\section{e) Six-word compounds:}

41. /ru-riy-ru-pak-ru-sao /

head-thousand-head-hundred-head-twenty

'captains of thousand, hundred and twenty persons'

42. /ray-kan-ploy-kan-thuk-kan /

consult-mutual-consider-mutual-decide-mutual

'mutual consultation, consideration and decision taken together'

Researches throw light into some interesting points on the formation and development of Tai Ahom compounds based on the historical documents, inscriptions, and copperplates of Tai Ahom (Borpatragohain, $2002 \&$ 2003; Buragohain, 2011). It is observed that in the earlier period short compounds were in use. For instance, /khup-poi / ('to kneel and prostrate') used in the early period was extended in the later period to /ma-khup-ma-poi / (come-kneel-come-prostrate, i.e., 'to come and prostrate in the Tai way'). Similarly, /ray / was used to denote 'to consult' in the earlier period which was later extended to /ray-kan / ('to consult together'). Further, it was extended to /ray-kan-ploy-kan-thuk-kan-sey-kan-bay-kan / ('oath taking by mutual consultation and consideration'). But it does not mean that short compounds were not used in later periods. On the whole, there was a tendency to use long compounds. In other words, compounds became phrasal in nature (Borpatragohain, $2002 \&$ 2003). Another important point to consider is that 


\section{Macrothink}

in the early periods, compounds were not very frequently used as observed in the ancient Ahom manuscripts. Moreover, some compounds of the early period had become obsolete; instead, new compounds had been introduced. Further, it would be interesting to investigate the nature of lexical combinations in Tai Ahom compounds found in the ancient manuscripts; but it is not in the scope of the current paper as it focuses mainly on describing the aspects of compounding in general.

\subsection{Semantic Compounds}

Tai Ahom compounds demonstrate various semantic constructions with the combination of head morpheme and a constituent part, or two semantic heads, or even two non-heads. For example,

43. /khroy-khroi /

goods-to be destroyed

'an alligator'

44. /phay-phok/

foreigner-to be white

'a white foreigner, the English'

In the examples above, none of the two constituents in the first compound acts as head and thus does not contribute directly to the meaning of the new word. However, in case of the second example, both constituents contribute as two semantic heads to the meaning of the new word.

Tai Ahom compounds also feature semantic reduplication. For instance, the compound /kon-di-phu-di / is employed to mean 'good men'. The meaning of /kon-di / ('man-good') is the same as /phu-di / (male-good) where /kon / and /phu / are head constituents and / di / is a modifier. It is important to note that compounds of this category always carry a plural sense.

\subsection{Syntactic Compounds}

In case of syntactic compounding formation, it is relevant to analyze and understand the word classes of the component words in compounding: whether the word class of the component words is relevant or lost in the process of compounding (Fabb, 2005, p. 71). Tai Ahom compounds include various constructions of Noun-Noun, Noun-Verb, Noun-Adjective, Verb-Verb, and so on. For example,

\subsection{Noun-Noun}

45. /kon-tai /

man-Tai

'Tai people'

46. Inam-khe /

water-river

'river water'

47. /nam-noy /

water-lake

'lake water' 


\section{INacrothink}

As shown in the examples above, noun compounds in Tai Ahom can have a noun as head and another as its attribute or modifier - similar to Thai noun compounds (see discussion in Section 5.5). In this case, the modifier constituent follows the head constituent.

\subsection{Noun-Verb}

48. /ti-nay /

place-to sit

'chair'

49. /ti-son /

place-to learn

'school'

50. /din-si /

soil-to burn

'brick'

In the examples above, the first constituent functions as the locative contributing primarily to the meaning of the new word.

\subsection{Noun-Adjective}

51. /doi-tam /

hill-low

'hillock'

5.14 Verb-Noun

52. /say-kham /

to clean-gold

'goldsmith'

53. /say-lik/

to clean-iron

'ironsmith'

54. /say-mo /

to clean-earthen pot

'potter'

In each of the examples above, the first constituent of the compound contributes to the functional aspect or attribute of the new word which is an agent noun. Whereas in case of verbal compounds, both constituents are combined to contribute to the functional aspects or attributes of the new word which is an agent noun. For example,

\subsection{Verb-Verb}

55. /say-kan /

to clean-to slip

'wrestler'

56. /say-mai/ 


\section{Macrothink}

to clean-to burn

'cook'

If the compound word is a collective noun, then it is possible to add some root words or other compound words with it in order to mean another collective noun. For example,

57. /roy-ren / or /hoy-hen /

to lift-house

'institute, school'

58. /hoy-hen-son-lik /

to lift-house-to learn-book

'school (where reading and writing are taught)'

59. /hoy-hen-son-lai-mu/

to lift-house-to learn-line-to draw

'handicrafts training school'

60. /hoy-hen-son-to-lai/

to lift-house-to learn-to weave-line

'weaving school'

61. /həy-hen-son-pin-sa-ru /

to lift-house-to learn-to get-good-knowledge

'teachers' training institute'

\subsection{Other Forms of Compounds}

Tai Ahom uses compounding to form gender-oriented words as there is no syntactic gender agreement in the language (Buragohain, 2011). To denote male and female identities, compounds are formed by adding masculine or feminine words as prefixes or suffixes to the nouns. Interestingly, kinship terms in Tai Ahom language are constructed in this way. The words indicating gender are suffixed with the kinship words. For example,
62. /luk-cai / child-MG
'male child (son)'
63. /luk-ney / child-FG
'female child (daughter)'
64. Inэy-cai/ young-brother+MG 'younger brother'
65. /nэy-sau / young-sister+FG 'younger sister'

In case of biped and quadruped animals, /phu / and /thek / are added respectively in order to denote the masculine gender, and /me / is used to denote the feminine gender. For example,

\subsection{Biped Animals}
66. /kai-phu /
fowl-MG 'cock'
67. /kai-me /
fowl-FG 'hen'
68. /nùk-phu /
bird-MG 'male bird'
69. Inùk-me /
bird-FG 'female bird'

\subsection{Quadruped Animals}

70. /say-thek/ elephant-MG 'male elephant' 


\section{$\triangle$ Macrothink}

71. /say-me/ elephant-FG 'female elephant'

72. Ima-thek/ horse-MG 'horse'

73. Ima-me/ horse-FG 'mare'

It is significant that prefixing or suffixing the gender markers in Tai Ahom indicates different connotations. For example,
74. /kai-me/ fowl-FG
'hen'
75. /mè-kai / FG-fowl 'mother hen that has chickens'
76. /hu-me/ cow-FG 'female cow'
77. /mè-hu/ FG-cow 'mother cow'
Similarly,
78. /say-thek/ elephant-MG 'male elephant, either big or small'
79. Ithek-say / MG-elephant 'big-sized or father elephant'
80. Ima-thek/ horse-MG 'male horse'
81. Ithek-ma / MG-horse 'big-sized or father horse'

There are some natural objects like the sun or the moon that are generally accepted as masculine in Tai Ahom. Whereas, some words are always used as feminine. In both cases, the markers are usually prefixed. However, gender marking is optional here. For example,
82. /khun-den / MG-moon 'the moon god'
83. /khun-ban / MG-sun 'the sun god'
84. /khun-phun /MG-rain 'the rain god'

Similarly,

\begin{tabular}{|c|c|c|}
\hline 85. /me-nam / & FG-river & 'river' \\
\hline 86. /me-mu / & FG-hand & 'the thumb of the hand' \\
\hline 87. /me-tin / & FG-foot & 'the thumb of the foot' \\
\hline 88. /me-lik/ & FG-letter & 'the alphabets' \\
\hline 89. /[bán]me-pi / & [day]FG-year & 'the last day of the tenth month of the year' \\
\hline
\end{tabular}

Another aspect of compounding in Tai Ahom is reduplication, more particularly in compounds with more than three words (see Section 5.7). The head constituent or the modifier of the compound is completely reduplicated to form the new word. For instance, the compound /kon-di-phu-di / ('good men') mentioned in Section 5.9 uses complete reduplication of the modifier morpheme /di /. Similarly, in case of the examples of c), d), and e) in Section 5.7, the head constituent is fully reduplicated. It is notable that such reduplicated structures always carry a plural sense.

\section{Conclusion}

The most significant aspect of word formation processes in Tai Ahom is the intensity of compounding found in the language. As mentioned earlier, the nature of monosyllabicity makes way for this richness in compounds. Tai Ahom demonstrates a great number of semantic and syntactic compound types. The language uses compounding for gender marking as well. Moreover, reduplication (both semantic and syntactic) is also used for forming varied 
structures of compounding. The primary challenge in studying the compounding formation in Tai Ahom lies in the fact that it is no longer used as a spoken language. Other challenges include its limited access (used in a few religious contexts) as well as its 'semi-speakers' with limited linguistic knowledge of it (Buragohain, 2018). The issues of contact and maintenance, endangerment and revival of Tai Ahom have already been addressed by researchers (Chatthip \& Wichasin, 1995; Morey, 2005; Morey, 2014). However, these issues are not covered within the scope of this research as it specifically aims at describing the formation of compounding in Tai Ahom. With no native speakers of the language left (apart from the priestly community who are the semi-speakers and use it occasionally in religious contexts), the only dependable source is undoubtedly the manuscripts and books written and recorded in this language. As these manuscripts and texts are preserved by the state government authorities of Assam as well as various Ahom families through generations, an informative description of the language is possible and recommended in order to initiate further research on independent as well as comparative study on the language.

\section{Conflict of interest statement}

The author hereby declares that there is no conflict of interest involved in this manuscript.

\section{Funding statement}

There is no funding involved in this manuscript.
Abbreviations
CL - Classifier
FG - Feminine Gender
MG - Masculine Gender
REL - Relative case marker

\section{References}

Abbi, A. (2001). A Manual of Linguistic Field Work and Structures of Indian Languages. Lincom Europa.

Arcodia, G. F., Grandi, N., \& Walchli, B. (2010). Coordination in Compounding. In S. Scalise, \& I. Vogel (Eds.), Cross-Disciplinary Issues in Compounding (pp. 177-198). Amsterdam - Philadelphia: John Benjamin. https://doi.org/10.1075/cilt.311.15arc

Barua, B., \& Deodhai, P. N. N. (eds.) (1991). Ahom Lexicons. Gauhati: Department of Historical and Antiquarian Studies in Assam.

Boonsawasd, A. (2012). Bouyei word formation, Studii de lingvistica, 2, 45-58.

Borpatragohain, B. (2002). Um Ra Khom Tai Tam Ahamiya. Simaluguri: The Khom Tai Publication.

Borpatragohain, B. (2003). Lik Peng Khom Tai Ahom. Simaluguri: Purbanchal Tai Sahitya Sabha, Assam.

Buragohain, D. (2011). A Descriptive Grammar of Tai Ahom. Ph.D. Thesis. Jawaharlal Nehru University, New Delhi.

Buragohain, D. (2013). Ancient Manuscript Literature in Tai Ahom. In A. K. Mishra, M. G. Wallang, \& C. S. Devi (Eds.), Studies in Linguistics of the Northeastern Languages. New Delhi: Lakshi Publishers. 


\section{Macrothink}

Education and Linguistics Research

ISSN 2377-1356 2019, Vol. 5, No. 2

Buragohain, D. (2018). Tracing the "extinctness" of Tai Ahom: issues of language loss and death. International Journal of the Sociology of Language, 2018(252), 163-177. https://doi.org/10.1515/ijsl-2018-0020

Diller, A., Jerold, A. E., \& Yongxian, L. (2008). The Tai-Kadai Languages. London: Routledge.

Fabb, N. (2005). Compounding. MIT Computer Science and Artificial Intelligence Laboratory project. http://www.ai.mit.edu/projects/dm/bp/fabb-compounds

Fasold, R. W. A. (1968). Noun Compounding in Thai. Ph.D. Thesis. University of Chicago, Washington.

Gohain, Aimyakhang (1997). Elementary Tai Primer with Grammar. Second edition. Dibrugarh: The Department of Assamese, Dibrugarh University.

Grierson, G. A., (ed.) (1903). Linguistic Survey of India. Mon-Khmer and Siamese-Chinese Families. Delhi: Low Price Publications.

Morey, S. (2014). Ahom and Tangsa: Case studies of language maintenance and loss in North East India, Language Documentation \& Conservation.

Morey, S. (2005). The Tai Languages of Assam - A Grammar and Texts. Canberra: Pacific Linguistics. http://www.hrelp.org/

Nartsupha, C., \& Ranoo, W. (1995). The state of knowledge of Ahom history, Tai Culture, 3(1). Guwahati: Eastern Tai Literary Association.

Phukan, J. N. (1966). The Tai Ahom Language, Lik Phan Tai, Vol. 1. Guwahati: Congress Press.

SIL International. (2002). Ethnologue: Languages of the World. (14th ed.). http://www.ethnologue.com/

\section{Copyright Disclaimer}

Copyright reserved by the author(s).

This article is an open-access article distributed under the terms and conditions of the Creative Commons Attribution license (http://creativecommons.org/licenses/by/3.0/). 